\title{
Large Rhizosphere Bacterial Diversity Exits Among Wild Progenitor Species of Modern Sugarcane (Saccharum Spp. Inter-Specific Hybrids)
}

\section{Mukesh Kumar Malviya}

Guangxi Academy of Agricultural Science

Chnag-Ning Li

Guangxi Academy of Agricultural Science

Manoj Kumar Solanki

Agricultural Research Organization Volcani Center

\section{Prakash Lakshmanan}

Guangxi Academy of Agricultural Science

\section{Rajesh Kumar Singh}

Guangxi Academy of Agricultural Science

\section{Krishan K Verma}

Guangxi Academy of Agricultural Science

\section{Pratiksha Singh}

Guangxi Academy of Agricultural Science

\section{Anjney sharma}

Guangxi Academy of Agricultural Science

\section{Qi-Qi Song}

Guangxi Academy of Agricultural Science

\section{Qian Nong}

Guangxi Academy of Agricultural Science

\section{Xiu-Peng Song}

Guangxi Academy of Agricultural Science

Yang-Rui Li ( $D$ liyr5745@126.com )

Guangxi Academy of Sciences https://orcid.org/0000-0002-7559-9244

\section{Research article}

Keywords: Rhizosphere soil, Sugarcane, 16S rRNA, nifH, Rhizobacteria, Diazotroph diversity

Posted Date: January 15th, 2021

DOI: https://doi.org/10.21203/rs.3.rs-144226/v1 
License: (c) (i) This work is licensed under a Creative Commons Attribution 4.0 International License. Read Full License 


\section{Abstract}

\section{Background}

Rhizosphere is rich in highly diverse and complex microbial communities. Plant growth promoting rhizpbacteria and diazotrops are played crucial role in plant growth and development. In this study, rhizosphere soils were collected from five wild Saccharum species- $S$. officinarum L. cv Badila (BRS), $S$. barberi Jesw. cv Pansahi (PRS), S. robustum (RRS), S. spontaneum (SRS), and S. sinense Roxb. cv Uba (URS) for studied of rhizosphere and diazotroph bacterial diversity using 16S rRNA and nifH gene amplification and sequencing.

Results

We detected a total of 6202 operational taxonomic units (OTUs) specific to the bacterial communities from all species combined. Out of the 107 bacterial communities detected among all samples, we found a core microbiome of 31 rhizobacterial families spread across all the species analyzed. A total of 1099 OTUs were identified for diazotrophs with a core microbiome of 9 families distributed among all the sugarcane species. The core microbiomes were distributed across twenty genera-Bradyrhizobium, Dechloromonas, Desulfovibrio, Stenotrophomonas, Xanthobacter, Anaeromyxobacter, Azospirillum, Pseudoacidovorax, Methylobacterium, Azoarcus, Paenibacillus, Ideonella, Beijerinckia, Paraburkholderia, Burkholderia, Ruficoccus, Geobacter, Sinorhizobium, Kosakonia, and Azotobacter.

Conclusion

The results presented here advance our understanding of rhizosphere associated bacterial diversity among genetically closely related wild species and provide a knowledge base for studying the evolution of rhizobacteria-host plant association during crop domestication.

\section{Background}

Rhizosphere is rich in highly diverse and complex microbial communities. These diverse microbial communities include saprophytes, epiphytes, endophytes, pathogens, and also plant growth promoting microorganisms [1]. Bacteria are the most abundant rhizospheric microbiota that other microbes, covering up to $15 \%$ of the total root surface [2]. It is reported that 2 to $5 \%$ of rhizobacteria are plant growth promoting in nature [3]. Many plant growth promoting rhizobacteria (PGPR) have been found to be associated with nitrogen fixation, solubilization of inorganic molecules like phosphate, production of plant growth regulators/hormones, siderophores and compounds that control phytopathogens $[4,5,6]$. Thus, PGPRs and other rhizosphere bacteria are now well recognized as essential parts of sustainable agriculture. The most commonly found rhizospheric bacterial genera are Bacillus, Pseudomonas, Rhizobia, Arthobacter, Agrobacterium, Micrococcus, Cellulomonas, Azotobacter, Alcaligenes, Mycobacterium and Flavbacter [7,8]. As the majority of PGPR are not culturable, studying them using traditional lab-based methods is highly cumbersome and time-consuming $[7,9]$. Advancements in 
molecular biology, especially the advent of high-throughput DNA sequencing technologies and the associated data analytics has helped understand the rhizosphere micro flora by culture-independent studies rapidly and at relatively low cost $[10,9]$. The next-generation sequencing approaches provide an efficient and comprehensive approach to identify microbial species in the rhizosphere irrespective of microbial abundance [11]. As a result, through the sequencing of 16S rRNA gene, the taxonomic characterization of highly diversified rhizospheric bacteria has increased remarkably [12,13]. Further, modern molecular techniques permit an in-depth analysis of soil bacterial communities' compositional and functional dynamics in changing soil environmental conditions, a recurring feature of agricultural soil $[9,14]$.

Sugarcane is an important agricultural crop grown in nearly 110 countries world wide. China is the third largest sugarcane producer (a collective term for Saccharum species, but more commonly applied to Saccharum officinarum $\mathrm{L}$. and Saccharum spp. inter-specific hybrids) and it is a major crop in southern China, accounting for $~ 90 \%$ of Chinese sugar production [15]. Over the years, sugarcane has been developed as a multi-purpose agro-industrial crop as it provides the raw material for different industries like food, thermal, energy/fuel, paper etc. $[16,17]$. Sugarcane is mostly grown as a monoculture for extended periods resulting in yield decline which is attributed to degraded soil, imbalanced soil biology, and build-up of pests and diseases. Restoration of soil biology and soil fertility is now emerging as a priority for improving soil health, reducing yield gap and sustaining profitable green agriculture. Hence, significant research is now being carried out on sugarcane rhizobacteria to understand their diversity and role in crop improvement. Several novel PGPRs from the sugarcane microbiome have been identified and used to improve crop production $[18,19]$. They are mostly involved in nitrogen fixation and plant hormone production, thus positively affecting sugarcane growth $[16,20,21]$. Rhizobacteria play a significant role in nitrogen fixation in sugarcane crops [22,23]. However, much remains to be learned about these diazotrophic rhizobacteria, a key driver of soil health and fertility. Our present study aims to understand the role of rhizosphere bacterial communities and identify new species of nitrogen fixing bacteria using high-throughput 16S rRNA and nifH gene sequencing by the Illumina platform. The current study reports interesting and novel findings on the diversity of bacterial communities in five Saccharum species namely, S. officinarum L. cv Badila (BRS), S. barberi Jesw. cv pansahi (PRS), S. robustum (RRS), $S$. spontaneum (SRS), and $S$. sinense Roxb. cv Uba (URS), and provides a knowledge base to study the influence of sugarcane genotype on rhizosphere bacteria in this necessary sugar and energy crop.

\section{Results}

This study analyzed the rhizosphere soil microbiota of five different critical ancestral sugarcane species using $16 \mathrm{~S}$ rRNA and nifH gene sequencing to understand their bacterial community diversity, especially that ofdiazotrophs.

\section{Data filtration, quality evaluation, and sequence optimization}


A total of 233,455 effective sequences number with an average length of 413 bp were obtained by sequencing $16 \mathrm{~S}$ rRNA from different sugarcane species samples. nifH gene sequencing resulted in a total of 182,185 effective sequences with $357 \mathrm{bp}$ average length from all the samples. Filtration of raw reads of $16 \mathrm{~S}$ rRNA and nifH genes was done using QIIME quality filters, followed by OTU identification, clustering, and analysis, respectively (Additional file 2: Table S1 and S2).

\section{Identification and analysis of Operational Taxonomic Units (OTUs)}

\section{Rarefaction curves}

To assess microbial diversity among all the sugarcane samples, a Rarefaction curve was drawn. The presence of OTUs across all the $16 \mathrm{~S}$ samples is shown in Additional file 1: Figure S1A. The highest number of OTUs was observed in $S$. sinense followed by S. robustum, $S$. barberi, $S$. officinarum and $S$. spontaneum. Presence of the OTUs identified in nifH sequence data across all the samples is shown in Additional file 1: Figure S1B. The highest number of OTUs was observed in S. barberi and S. sinense followed by S. robustum and S. spontaneum. The clustering of OTUs was done based on $97 \%$ sequence similarity.

\section{Rank abundance curves (RACs)}

Comparison of rank abundance based on OTU ranks derived from 16S rRNA and nifH sequences (Additional file 1: Figure S2 A and B) was performed to visualize the relative species abundance across all the samples. RACs depict the species richness and species evenness, which help identify common and rare rhizobacterial species in the sugarcane species studied. Figure S2A, revealed that all the sugarcane samples showed high abundance at least OTU ranks i.e. 1, following this at 500 OTU rank equal species richness and evenness was displayed. At the highest OTU rank, i.e. 1000, all the samples showed least species abundance and high species evenness. S. sinense samples displayed the highest species richness among all the samples at highest OTU rank. But in (Additional file 1) Figure S2B, S. barberi samples displayed the highest species richness among all the samples at highest OTU rank. The $S$. spontaneum sample, compared to all the other samples, showed less species evenness at low OTU rank, i.e. approximately 180 .

\section{Venn diagrams}

We analyzed common and unique OTUs based on 16S rRNA and nifH gene sequences for each sample in the Venn diagram (Figure 1A \& B). In the 16S rRNA sequence data, 6202 OTUs were identified collectively, of which 519 OTUs were common across all samples. According to the Venn diagram, the relative frequency of OTUs in the studied species is as follows: $S$. sinense $>$ S.robustum $>$ S.barberi>S. officinarum $>S$. spontaneum. The highest number of OTUs was recorded in S. sinense. A total of 1099 OTUs were identified in all the samples of nifH gene sequence data. Among them, 14 were common OTUs found across all the samples. According to the Venn diagram, occurrence of OTUs in the plant samples was as follows: S. barberi $>$ S. robustum $>S$. officinarum $>$ S. sinense $>S$. spontaneum. The highest numbers 
of OTUs were found in $S$. barberi and, $S$. spontaneum had the lowest number of OTUs for both 16S rRNA and nifH gene sequence data.

\section{Principal component analysis (PCA)}

To understand the rhizobacterial community composition, PCA plots were generated based on 16S rRNA and nifH gene samples OTUs data (Figure S3 A and B). The OTUs present in the $16 \mathrm{~S}$ samples shows that $S$. officinarum and $S$. robustum are not identical, $S$. sinense and $S$. robustum are more similar, and $S$. spontaneum is distinct from all the other samples (Figure S3 A). PCA of nifH gene samples showed a close identity between $S$. barberi and $S$. spontaneum whereas $S$. sinense, $S$. officinarum and S. robustum remained distinct to one another.

\section{Alpha diversity}

Alpha diversity refers to the diversity within a particular sample individually, and it is usually represented by the species (i.e. species richness) enumerated in the test samples. Alpha diversity analysis was done using Shannon, Simpson and Chao Indices Rarefaction curves for both $16 \mathrm{~S}$ and nifH sequence data. Additional file 1: Figure S4 A consists of two plots displaying Shanon, Simpson, and Chao Indices, built using $16 \mathrm{~S}$ samples. The Shannon Index increased as both the species richness and the evenness in the community increase. Among the 16S rRNA data of all the samples analyzed, Shanon and Chao Index of $S$. sinense sample was the highest as compared to the other four samples with little variation among themselves. Whereas, Simpson Index increased as diversity increased. In the Simpson Index plot, $S$. officinarum sample showed the highest value implying that it has more species diversity compared to the other four samples. Shannon and Chao Index of nifH gene data of all the samples showed more species diversity in $S$. barberi sample than others. According to the Simpson Index, of $S$. officinarum sample was the highest compared to other (Additional file 1: Figure S4 B).

\section{Community composition analysis}

The relative abundance of the microbial communalities differed among five sugarcane species analyzed. The abundant phyla identified in $16 \mathrm{~S}$ samples in all sugarcane species are Proteobacteria, Firmicutes, Actinobacteria, Acidobacter, Bacteroidetes, Chloroflexi, Gemmatimonadetes, Planctomycetes and Nitrospirae (Figure 2A). Firmicutes were the highest phyla present in S. officinarum compare to other samples. Gemmatimonadetes was the highest in S. barberi, Acidobacter was highest in S. spontaneum, and Bacteroidetes was highest in $S$. sinense. Based on nifH gene samples, we observed the occurrence of Proteobacteria and Verrucomicrobia (Figure 2B). Firmicutes were abundant in S. spontaneum samples compare to other samples. Many unclassified phyla were also represented abundantly in S. spontaneum followed by $S$. sinense and $S$. barberi samples.

Genus distribution using 16S rRNA sequence data (Figure 3A) showed Bacillus, Pseudomonas, Pseudoarthobacter, Massilia, Lysobacter, Nitrospira, Gemmatimonas, Streptomyces, and Rhizobiumweremost abundant in S. officinarum whereas $S$. barberi sample was dominated by Bacillus, 
Pseudomonas, Pseudoarthobacter, Lysobacter, Gemmatimonas, and Sphingomonas species. Bacillus, Pseudomonas, Pseudoarthobacter, Massilia, Nitrospira, Gemmatimonas, Streptomyces, Paenibacillus, and Dechloromonaswere reported in S. robustum. S. spontaneum sample contained Pseudomonas, Pseudoarthobacter, Massilia, Tumebacillus, Remibacter, Sphingomonas, and Skermanelia. Bacillus, Pseudomonas, Pseudoarthobacter, Massilia, Lysobacter, Nitrospira, Faecalibacterium and Streptococuswere detected in S. sinense. Bacillus was the most abundant genus in S. officinarum, $S$. robustum and $S$. sinense while Pseudomonas became the number one genus in $S$. barberi and $S$. spontaneum.

Genus distribution using nifH gene data is presented in Figure 3B. Bradyrhizobium, Dechloromonas, Desulfovibrio, and Stenotrophomas were abundant in S. officinarum, while Bradyrhizobium, Desulfovibrio, Xanthobacter and Anaeromyxobacter were the leading genera in S. barberi. Bradyrhizobium, Dechloromonas, Desulfovibrio, and Anaeromyxobacter were the dominant groups in S. robustum. $S$. spontaneum contained Bradyrhizobium, Azospirillum, Methanobacterium, and Paenibacilllus species. Bradyrhizobium, Dechloromonas, Xanthobacter and Anaeromyxobacterwere present in S. sinense. Genus Burkolderia was found in S. barberi, S. spontaneum, and S. sinense while Beijerinckia was recorded in $S$. barberi, $S$. spontaneum, and $S$. sinense. Genus Idenella was commonly present in all the samples except S. spontaneum and Kosakonia was commonly present in S. barberi and S. spontaneum.

\section{KRONA analysis}

The KRONA software was used to visualize the species annotation results, in which the circles represent different points from the inside out class level, the size of the fan represented the relative proportions of the results of different OTU comments (Figure 4). Species annotation results visualized with KRONA identified Bacillus, Pseudomonas, Pseudoarthobacter, Rhizobiales, Burkholderiales, Massilia and Streptomyces as the most dominant ones (Figure 4A). Similar analyses carried out with nifH OTUs showed Bradyrhizobium, Dechloromonas, Desulfovibrio, Stenotrophomonas, Anaeromyxobacter etc. as the most common genera identified (Figure 4B). The relative abundance of the top twenty diazotrophs at the genus level present in all sugarcane species is shown in Figure 5. Diazotrophs belonging to the genus Bradyrhizobium were present in all the samples tested.

\section{Star analysis of all the sugarcane samples}

Star analysis was conducted using the top 10 genera of each sample. Star analysis for both $16 \mathrm{~S}$ and nifH sequence data are presented in Additional file 1: Figure S5 A\&B. Top 10 genera used for the 16S data based analysis were Pseudoarthobacter, Pseudomonas, Bacillus, Massilia, Gemmatimonas, Nitrospora, Haliangium, Ramibacter, Tumebacillus and Lysobacter. From this analysis, Bacillus genus was found high in S. officinarum and S. robustum samples, while Pseudomonas was the dominant one in S. barberi, $S$. robustum, S. spontaneum and $S$. sinense. Tumebacillus genus was found only in $S$. spontaneum. Similarly, star analysis for nifH gene samples identified the presence of Bacillus in all the samples. Desulfovibrio was found in S. officinarum, S. robustum and S. barberi in significant numbers. Xanthobacter was abundant in S. sinense. Anaeromyxo bacter was found in all the samples except that 
of S. spontaneum. Pseudoacidovorax genus was found only in S. robustum, S. barberi and S. sinense samples. Azospirillum and Methylobacterium were unique to $S$. spontaneum.

\section{Beta diversity}

Beta diversity measures species diversity among different samples collected from different or similar environments. We performed the principal coordinated analysis ( $\mathrm{PCOA}$ ) and UniFrac-based cluster analysis to understand the beta diversity of 16S rRNA and nifH gene in the sugarcane species studied (Figures $6 \&$ 7). Based on 16S rRNA data, S. sinense, along with S. barberi, and S. officinaruma long with $S$. robustum, formed independent clusters. And, S. spontaneum segregated away from all others, displaying higher beta diversity. The same was found true for nifH gene analysis (Figure 7A). Hierarchical clustering based on the UniFrac cluster analysis showed similar results for both 16S rRNA and nifH gene data, containing similar identical sequences showing 0 (blue colour) distances. $S$. sinense to $S$. spontaneum showed more distance (red colour $=0.3$ ) indicating dissimilarity in sequences of $S$. sinense to $S$. spontaneum samples (Figure 6A and 7B).

The distribution of dominant genera based on their relative abundance performed with Bray-Curtis algorithm showed Bacillus being the dominant genus in all the samples except those from $S$. Spontaneum (Figure 8). Second dominant genus identified was Pseudomonas, while Pseudoarthobacter was the third leading one. S. spontaneum showed the presence of most unidentified genera in our analysis. Similarly, distribution of dominant genera in nifH samples showed the presence of Dechloromonas sp. abundant in all samples except those from S. barberi. Xanthobacter and Bradyrhizobiumg were found to be dominant in S. Officinarum and S. sinense, respectively (Figure 9).

\section{Discussion}

There are several reports of identification and characterization of plant growth promoting rhizobacteria from sugarcane [34,35] and other crops [36-38] and they are also being used for crop productivity improvement. Most of the sugarcane studies are conducted with modern cultivated sugarcane hybrid varieties and there is no previous attempt to understand the diversity of rhizobacteria in its wild progenitors and closely related species such as $S$. officinarum, $S$. spontaneum, $S$. robustum, $S$. barberi and $S$. sinensis as we did in this study. Here, we used high-throughput sequencing of 16S rRNA and nifH genes to study the rhizobacterial diversity and complexity in sugarcane species. Rhizospheric microorganisms are known to interact with plants for their survival and nutritional requirements $[39,40]$. Many of them are also beneficial bacteria to help plants with nutrient uptake and to cope with pathogens and abiotic stresses $[18,41,42]$. Considering the large microbial diversity in the rhizosphere, a large number of PGPRs are yet to be identified for various crops, including sugarcane. Bacteria are the most abundant of all the rhizospheric microbiota, and many are known to promote plant growth $[2,3,42]$. Our study made an effort to understand the diverse and complex diazotroph bacterial communities present in the rhizospheric soils of progenitors and closely related speciesof modern sugarcane hybrids as nitrogen fixation plays a critical role in its growth and production [43,22]. 
16S rRNA sequence data revealed 6202 OTUs assigned to different bacterial species colonizing rhizosphere of different sugarcane species studied. Analysis of these OTUs showed that $S$. sinense rhizosphere has the largest number of rhizobacterial communities compared to other related species studied here. Besides this, alpha diversity analysis also predicted the highest bacterial diversity in $S$. sinense samples. However, other sugarcane species also showed considerable species diversity. Phylum level distribution studies identified the dominance of Proteobacteria, Firmicutes, Actinobacteria, Bacteroidetes, Chloroflexi, Gemmatimonadetes, Planctomycetes and Nitrospirae. Many of them were reported to be present in sugarcane rhizosphere previously [44]. Out of the total OTUs identified, 1099 were from diazotrophs based on nifH gene data. Analysis of nifH gene sequence variation helped identify the top twenty genera (Bradyrhizobium, Dechloromonas, Desulfovibrio, Stenotrophomonas, anthobacter, Anaeromyxobacter, Azospirillum, Pseudoacidovorax, Methylobacterium, Azoarcus, Paenibacillus, Ideonella, Beijerinckia, Paraburkholderia, Burkholderia, Ruficoccus, Geobacter, Sinorhizobium, Kosakonia and Azotobacter). Out of these, ten were found to fix nitrogen in sugarcane and other plants.

Bradyrhizobium is known to fix nitrogen in sorghum and sugarcane $[45,46]$. Members of Sinorhizobium genus are also known to fix nitrogen symbiotically in leguminous alfalfa plants [47]. Azotobactergenus consists of seven different species and they are involved in atmospheric nitrogen fixation in different crop plants [48]. Azotobacter and Beijerinckia were studied for diazotrophic attributes in early 1960s in rice and other cereal crops $[49,50]$. Contrary to Azotobacter, Beijerinckia genus is largely restricted to the tropics and its nitrogen fixation ability has been reported in a variety of plants [51]. Kosakonia spp. fix nitrogen on cucumber roots [52]. Roots of switchgrassare inhabited with nitrogen-fixing bacteria belonging to Dechloromonas, Desulfovibrio, Azoarcus, Ideonella, Paraburkholderia and Burkholderia [53]. It is hard to identify and classify most of the bacteria in culture because of their morphological similarities. But, culture-independent methods like 16S rRNA sequencing and highly efficient, costeffective and provide accurate identification and classification of rhizobacteria. Overall, the dominant genera identified in this study are known to fix atmospheric nitrogen for plant growth.

In the present study, we observed a few taxa such as Proteobacteria, Acidobacteria, Actinobacteria, Firmicute, Sphingomonas, Bradyrhizobium, and Gemmatimonas were dominant while genus such as Bacillus, Pseudomonas, Bradyrhizobium, Burkholderiaand rhizobium were dominant. In our previous studies, we observed that some taxa such as Proteobacteria, Acidobacteria, Actinobacteria, Firmicute, Bacteroidetes, Sphingomonas, Bradyrhizobium, Bryobacter, and Gemmatimonas were always present in the sugarcane rhizosphere [54,55]. Some genus such as Bacillus, Pseudomonas, Burkholderia, known for their plant growth promoting and nitrogen fixating properties, were found to be enriched in the sugarcane rhizosphere [56,22,23]. Community composition analysis of $16 \mathrm{~S}$ rRNA sequence data helped in tracking phylum and genus level distribution of rhizobacteria among different sugarcane species studied.

Interestingly, we observed the presence of a few genera, namely Streptococcus, Rhodanbacter, Anaeromyxo bacter and Prevotella common among all the species studied here. The members of these genera were found commonly in soil and can colonize crop plants. From the previous reports it appears that Rhodanbacter, Anaeromyxobacter and Prevotella genera were isolated from different soil and plant sources and they were found to have nifH gene and nitrogen fixation abilities [57-59]. Thus, we believe 
that more characterization of these bacteria colonizing the sugarcane rhizosphere will be beneficial for developing bio-based crop products to improve sugarcane crop productivity.

Diversity among these nitrogen fixing bacteria was revealed by alpha and beta diversity analyses. The top ten genera with the highest abundance were found to be Bacillus, Desulfovibrio, Xanthobacter, Anaeromyxobacter, Pseudoacidovorax, Azospirillum and Methylobacterium. Among these Bacillus is a common bacterial diazotroph in sugarcane [60]. Desulfovibrio, Anaeromyxobacter, Azospirillum and Xanthobacter are nitrogen fixers in rice [61-64]. Methylobacterium is a nitrogen fixing bacterium, found in legumes [65], but such a function was not reported for Pseudoacidovorax.

\section{Conclusions}

All the sugarcane species studied here showed a significant number of nitrogen fixing rhizobacteria, which strengthens the contention, that exploring rhizosphere bacteria may help develop a sustainable low sugarcane crop production system meeting its $\mathrm{N}$ requirement from atmospheric nitrogen fixation requiring low nitrogen fertilizer input. Substantial genetic variation for rhizobacteria and diazotrophs communities exists among different progenitors and closely related species of modern cultivated sugarcane hybrids. However, considering the wide natural habitats of these wild species spanning both, tropics and sub-tropics, similar studies using accessions sourced from different locations and environmental conditions will greatly advance our understanding of sugarcane rhizo-microbiome. Future research should also focus on isolation and practical application of beneficial plant growth promoting rhizobacteria and diazotrophs. Filling the large knowledge gap on microbiota and sugarcane interactions is critical for exploiting these beneficial microbes for sustainable sugarcane agriculture.

\section{Methods}

\section{Sample collection}

Rhizospheric soil of five sugarcane species, S. officinarum L. cv. Badila (BRS), S. barberi Jesw. cv. pansahi (PRS), S. robustum (RRS), S. spontaneum (SRS), and S. sinense Roxb.cv. Uba (URS) were collected from the sugarcane germplasm collection of Sugarcane Research Institute, Guangxi Academy of Agricultural Sciences, Nanning, Guangxi, China. The soil compositions of all the root collection sites are presented in Additional file: 2 Table S3. We sampled three soil samples randomly from each species and were used for DNA isolation.

\section{Bacterial genome isolation and sequencing}

\section{Extraction of genomic DNA}

We used a culture-independent method [24] to study the bacterial composition of rhizospheric microbiome collected from the test species. Total microbial DNA was extracted using CTAB/SDS isolation method with minor modifications [25]. The purity and concentration of DNA preparations were 
determined using $1 \%$ agarose gel electrophoresis. DNA samples diluted to $1 \mathrm{ng} \mathrm{DNA} / \mu \mathrm{L}$ using sterile water and used for further analysis. We mixed three DNA samples of each sugarcane species in the same concentration to get a mixed sample. Mixed samples were used for the sequencing analysis.

\section{Identification of 16S rRNA and nifH genes}

Microbial 16S rRNA was amplified with the universal primers 341F (ACTCCTACGGGAGGCAGCAG) and 806R (GGACTACHVGGGTWTCTAAT), which target the V3-V4 region. The nifH gene was amplified with primers Pol-F (TGCGAYCCSAARGCBGACTC) and Pol-R (ATSGCCATCATYTCRCCGGA), as previously reported [26]. Polymerase chain reaction (PCR) amplification of identified 16S rRNA and nifH genes was performed with Phusion ${ }^{\circledR}$ High-Fidelity PCR Master Mix (New England Biolabs). Thermal cycling consisted of initial denaturation at $98^{\circ} \mathrm{C}$ for $1 \mathrm{~min}$, followed by 30 cycles of denaturation at $98^{\circ} \mathrm{C}$ for 10 $\mathrm{s}$, annealing at $50^{\circ} \mathrm{C}$ for $30 \mathrm{~s}$, and elongation at $72^{\circ} \mathrm{C}$ for $60 \mathrm{~s}$, finally, $72^{\circ} \mathrm{C}$ for $5 \mathrm{~min}$, following the protocols reported previously by Zhou et al.[27].

\section{PCR product quantification and Library preparation and sequencing}

Visualization and quantification of PCR products were conducted by mixing an equal volume of $1 \times$ loading buffer containing SYB green dye with the PCR products and electrophoresed on $2 \%$ agarose gel. The 400-450bp DNA fragments were isolated and used for further experiments. Equimolar amounts of PCR products from all samples were pooled and the mixture was purified using Qiagen Gel Extraction Kit (Qiagen, Germany). Sequencing libraries of purified amplicons were generated using TruSeq ${ }^{\circledR}$ DNA PCRFree Sample Preparation Kit (Illumina, USA) in accordance with manufacturer's protocol and index codes were added. The library quality and concentration were assessed on the Qubit@ 2.0 Fluorometer (Thermo Scientific) and Agilent Bioanalyzer 2100 system. To perform sequencing the qualified libraries were fed into the IlluminaHiSeq2500 platform.

\section{Data analysis}

\section{Quality control and sequence assembly}

Based on their unique barcode, trimming of barcode and primer sequencing were done. Reads were assembled using FLASH (V.1.2.7) (http://ccb.jhu.edu/software/FLASH/) [28] to generate raw tags. To obtain high quality clean tags from raw tags, we performed quality filtration using QIIME (V1.7.0) (http://qiime.org/index.html) [29]. Removal of chimera sequences was done by comparing the tags with the reference database Unite Database (https://unite.ut.ee/) using UCHIME algorithm (http://www.drive5.com/usearch/manual/uchime_algo.html) [30]. The above step is critical to obtain effective tags.

\section{Operational Taxonomic Unit (OTU) cluster and species annotation}

\section{OTU identification}


Operational Taxonomic Units identification was done with UPARSE software (v.7.0.1001) (http://drive5.com/uparse/) [31]. Based on $\geq 97 \%$ of sequence similarity, all the effective tags were clustered into OTUs. For each OTU cluster, a representative sequence was screened to perform taxonomic annotation.

\section{Species annotation}

OTUs were taxonomically annotated following a BLAST analysis against the Unite Database of each identified representative bacterial sequence done in QIIME software.

\section{Phylogenetic relationship construction}

Multiple sequence alignment was conducted with MUSCLE software (V.3.8.3) (1http://www.drive5.com/muscle/) [32], and phylogenetic relationship of different OTUs was established to understand the diversity of microbial species in various samples (groups).

\section{Data normalization}

Standard sequence number given to samples with least sequences was considered for OTUs abundance information normalization. Subsequently, alpha diversity and beta diversity analysis were conducted based on the normalized data.

\section{Alpha diversity}

Alpha diversity analysis is carried out to find the complexity of species diversity for each sample using 6 indices, which include observed species, Chao1, Shannon, Simpson, abundance-based coverage estimator (ACE) and Good's coverage. Indices calculation for all the samples was done using QIIME and visualized in R software (V. 2.15.3). Community richness was identified with two selected indices using Chao - the Chao1 richness estimator (http://www.mothur.org/wiki/Chao). Whereas, the Shannon index (http://www.mothur.org/wiki/Shannon) and Simpson index (http://www.mothur.org/wiki/Simpson) indices were used for identification of community diversity in all the samples. To characterize the sequencing depthandcoverage, the Good's coverage (http://www.mothur.org/wiki/Coverage) was used.

\section{Beta diversity}

To evaluate the differences in bacterial species among all the samples, beta diversity analysis was performed. QIIME software was used to calculate beta diversity using weighted and unweighted UniFrac distances.

\section{Statistical analysis}

Cluster analysis followed by principal component analysis (PCA) was applied to reduce the dimensionality and preserve the variability information of the sample data. Using the FactoMineR and ggplot2 packages in R software, results were visualized. Later, Principal Coordinate Analysis (PCoA) was 
performed to obtain principal coordinates and to visualize them. To compare microbial diversity present in different samples, the UniFrac method was used to generate weighted or unweighted UniFrac values among samples that were transformed to give uncorrelated/orthogonal axes. Visualization of PCoA results was done using WGCNA package, stat and ggplot2 packages in R software. QIIME software was used for hierarchical clustering by Unweighted Pair-group Method with Arithmetic Mean method (UPGMA) [33] to infer the distance matrix using average linkage. The raw data of 16S rRNA (Accession no.

PRJNA678588) and nifH gene (Accession no. PRJNA681283) were submitted to the NCBI Sequence Read Archive.

\section{Abbreviations}

BRS: S. officinarum L. cv Badila; PRS: S. barberi Jesw. cv Pansahi; RRS: S. robustum; SRS: S. spontaneum; URS: S. sinense Roxb. cv Uba; OTUs: Operational taxonomic units; PCoA: Principal coordinate analysis; QIIME: Quantitative insights into microbial ecology; PCR: Polymerase chain reaction; RACs: Rank abundance curves

\section{Declarations}

\section{Ethics approval and consent to participate}

Not applicable.

\section{Consent for publication}

Not applicable.

\section{Availability of data and materials}

The raw data of 16S rRNA (Accession no. PRJNA678588) and nifH gene (Accession no. PRJNA681283) are available in NCBI SRA in following links. https://www.ncbi.nlm.nih.gov/Traces/study/? acc=PRJNA678588; https://www.ncbi.nlm.nih.gov/sra/PRJNA681283.

\section{Competing interests}

The authors declare that they have no competing interests.

Funding: This work was supported by grants from the National Natural Science Foundation of China (Grant Numbers 31471449 to YRL), Natural Science Foundation of Guangxi Province (Grant Numbers 2016GXNSFAA380126 and 2019GXNSFDA185004 to CNL), Guangxi Innovation Term of Modern Agriculture Technology (Grant Numbers gjnytxgxcxtd-03-01 to YRL), and Guangxi R\&D Program (Grant Numbers GKG1598006-1-1 and GuiKeAD17195100 to YRL). 
Author Contributions: Conceived and designed the experiments: MKM, CNL, \& YRL. Performed the experiments: MKM \& CNL. Analyzed the data: MKM, CNL, \& MKS. Contributed reagents/materials/analysis tools: MKM, RKS, KKV, PS, AS, QQS, QN and XPS. Wrote the paper: MKM \& $\mathrm{PL}$. All authors have read and agreed to the published version of the manuscript.

Acknowledgements: National Natural Science Foundation of China, China Postdoctoral Foundation, Guangxi Innovation Term of Modern Agriculture Technology, and Guangxi Academy of Agricultural Sciences, Nanning, Guangxi, China, for providing the necessary facilities for this study.

\section{References}

1. Avis TJ, Gravel V, Antoun, $H$, Tweddell RJ. Multifaceted beneficial effects of rhizosphere microorganisms on plant health and productivity. Soil Biol Biochem. 2008;40:1733-1740. https://doi.org/10.1016/j.soilbio.2008.02.013.

2. van Loon, LC. Plant responses to plant growth promoting bacteria. Eur J Plant Pathol. 2007; 119:243-254.

3. Antoun $\mathrm{H}$, Prévost D. Ecology of plant growth promoting rhizobacteria. In PGPR: Biocontrol and biofertilization. 2005;1-38.

4. Velineni, S.; Brahmaprakash, G.P. Survival and phosphate solubilizing ability of Bacillus megaterium in liquid inoculants under high temperature and desiccation stress. J Agri Sci Tech. 2011;13:795802.

5. Jangu OP, Sindhu SS. Differential response of inoculation with indole acetic acid producing Pseudomonas sp. in green gram (Vignaradiata L.) and black gram (Vignamungo L.). Microbiol. J. 2011;1:159-73.

6. Cawoy H, Bettiol W, Fickers P, Ongena M. Bacillus-based biological control of plant diseases. Pesticides in the modern world-pesticides use and management. 2011; 21: 273-302.

7. Prashar P, Kapoor N, Sachdeva S. Rhizosphere: its structure, bacterial diversity and significance. Rev Environ Sci Biotechnol. 2014;13:63-77.

8. Teixeira LC, Peixoto RS, Cury JC, Sul WJ, Pellizari VH, Tiedje J, et al. Bacterial diversity in rhizosphere soil from Antarctic vascular plants of Admiralty Bay, maritime Antarctica. ISME J. 2010; 4:9891001.doi: 10.1038/ismej.2010.35.

9. Wei YJ, Wu, Y, Yan, YZ, Zou W, Xue J, Ma WR, et al. High-throughput sequencing of microbial community diversity in soil, grapes, leaves, grape juice and wine of grapevine from China. PloS one. 2018;13. doi: 10.1371/journal.pone.0193097.

10. Reuter JA, Spacek DV, Snyder MP. High-throughput sequencing technologies. Mol. cell. 2015; 58:586-97.

11. Uroz S, loannidis P, Lengelle J, Cébron A, Morin E, Buée M, et al. Functional assays and metagenomic analyses reveals differences between the microbial communities inhabiting the soil horizons of a Norway spruce plantation. PLoS One. 2013,8. doi:10.1371/journal.pone.0055929. 
12. Dong L, Xu J, Zhang L, Yang J, Liao B, Li X, et al. High-throughput sequencing technology reveals that continuous cropping of American ginseng results in changes in the microbial community in arable soil. Chin Med. 2017;12:18. doi: 10.1186/s13020-017-0139-8.

13. Gong B, Cao H, Peng C, Perčulija V, Tong G, Fang H. High-throughput sequencing and analysis of microbial communities in the mangrove swamps along the coast of Beibu Gulf in Guangxi, China. Sci. Rep. 2019; 9:1-0. doi: 10.1038/s41598-019-45804-w.

14. Dini-Andreote F, Andreote FD, Costa R, Taketani RG, van Elsas, JD, Araújo WL. Bacterial soil community in a Brazilian sugarcane field. Plant soil. 2010;336:337-49.

15. Li YR, Yang LT. Sugarcane agriculture and sugar industry in China. Sugar Tech. 2015;17: 1-8.

16. Goldemberg J, Coelho ST. Guardabassi P. The sustainability of ethanol production from sugarcane. Energy policy. 2008;36:2086-97.

17. Fischer D, Pfitzner B, Schmid M, Simoes-Araujo JL, Reis VM, Pereira W, et al. Molecular characterization of the diazotrophic bacterial community in uninoculated and inoculated field-grown sugarcane (Saccharum sp.). Plant Soil. 2012;356:83-99. doi: 10.1007/s11104-011-0812-0.

18. Pisa G, Magnani GS, Weber H, Souza EM, Faoro H, Monteiro RA, et al. Diversity of 16S rRNA genes from bacteria of sugarcane rhizosphere soil. Braz J Med Biol Res. 2011; 4:1215-21. doi: $10.1590 /$ s0100-879x2011007500148.

19. Armanhi JS, de Souza RS, Damasceno ND, de Araújo LM, Imperial J, Arruda PA. Community-based culture collection for targeting novel plant growth-promoting bacteria from the sugarcane microbiome. Front. Plant Sci. 2018;8:2191. doi: 10.3389/fpls.2017.02191.

20. Fuentes-Ramirez LE, Caballero-Mellado J. Bacterial biofertilizers. In PGPR: Biocontrol and biofertilization. 2005; 143-172. Springer, Dordrecht, The Netherlands.

21. Mehnaz, S. Plant growth-promoting bacteria associated with sugarcane. In Bacteria in Agrobiology: Crop Ecosystems. 2011;165-187. doi: 10.4014/jmb.1005.05014.

22. Li HB, Singh RK, Singh P, Song QQ, Xing YX, Yang LT, et al. Genetic diversity of nitrogen-fixing and plant growth promoting Pseudomonas species isolated from sugarcane rhizosphere. Front Microbiol. 2017; 8:1268. doi:10.3389/fmicb.2017.01268.

23. Malviya MK, Solanki MK, Li CN, Htun R, Singh RK, Singh P, Yang LT, Li YR. Beneficial linkages of endophytic Burkholderi aanthina MYSP113 towards sugarcane growth promotion. Sugar Tech. 2019. doi.org/10.1007/s12355-019-00703-2.

24. Ranjard L, Poly F, Nazaret S. Monitoring complex bacterial communities using culture-independent molecular techniques: application to soil environment. Res Microbiol. 2000; 151:167-77.doi: 10.1016/s0923-2508(00)00136-4.

25. Barbier FF, Chabikwa TG, Ahsan MU, Cook SE, Powell R, Tanurdzic M, et al. A phenol/chloroform-free method to extract nucleic acids from recalcitrant, woody tropical species for gene expression and sequencing. Plant methods. 2019;15:62. doi: 10.1186/s13007-019-0447-3.

26. Poly, F.; Monrozier, L.J.; Bally, R. Improvement in the RFLP procedurefor studying the diversity of nifH genes in communities of nitrogen fixers in soil.Res. Microbiol. 2001;152, 95-103. doi: 
10.1016/S0923-2508(00)01172-4.

27. Zhao Y, Bi K, Gao Z, Tao C, Liu H, Xie J, Cheng J, Fu Y, Jiang D. Transcriptome Analysis of Arabidopsis thaliana in response to Plasmodiophora brassicae during early Infection. Front Microbiol. 2017;8: 673.

28. Magoè T, Salzberg SL, FLASH: fast length adjustment of short reads to improve genome assemblies. Bioinformatics. 2011;27: 2957-2963. doi: 10.1093/bioinformatics/btr507.

29. Caporaso J, Gregory et al. QIIME allows analysis of high-throughput community sequencing data. Nat. Methods. 2010;7.5:335-336.

30. Edgar RC, Haas BJ, Clemente JC, Quince C, Knight R. UCHIME improves sensitivity and speed of chimera detection. Bioinform. 2011;27.16:2194-2200.

31. Edgar RC. UPARSE: highly accurate OTU sequences from microbial amplicon reads. Nat methods. 2013;10:996. doi: 10.1038/nmeth.2604.

32. Edgar, RC. MUSCLE: a multiple sequence alignment method with reduced time and space complexity. BMC bioinformatics. 2004;5:113.

33. Sokal M. A statistical method for evaluating systematic relationships.University of Kansas Science Bulletin.1958;38:1409-1438.

34. Inui - Kishi RN, Kishi, LK, Picchi, SC, Barbosa JC, Lemos MTO., Marcondes J, ElianaGertrudes de MacedoLemos EGdeM. Phosphorus solubilizing and IAA production activities in plant growth promoting rhizobacteria from Brazilian soils under sugarcane cultivation. ARPN J Eng Appl Sci. 2012;7(11):1819-6608.

35. Lamizadeh E, Enayatizamir N, Motamedi H. Isolation and Identification of Plant Growth-Promoting Rhizobacteria (PGPR) from the Rhizosphere of Sugarcane in Saline and Non-Saline Soil. Int. J. Curr. Microbiol. App. Sci. 2016; 5(10),1072-1083.

36. Kumar A, Maurya BR, Raghuwanshi R. Isolation and characterization of PGPR and their effect on growth, yield and nutrient content in wheat (Triticumaestivum L.). Biocatalysis and Agricultural Biotechnology. 2014;3(4):121-128.

37. Gaikwad S, Sapre V. Structural and Functional Diversity of Rhizobacterial Strains Isolated from Rhizospheric Zone of Different Plants of Sholapur- Maharashtra Region, India. Int J Curr Microbiol App Sci. 2015;4(9):263-273.

38. Tsegaye Z, Gizaw B, Tefera G, Feleke A, Chaniyalew S, Alemu T, Assefa F. Isolation and biochemical characterization of Plant Growth Promoting (PGP) bacteria colonizing the rhizosphere of Tef crop during the seedling stage. J Plant Sci Phytopathol. 2019;3:013-027.

https://doi.org/10.29328/journal.jpsp.1001027.

39. Berendsen RL, Pieterse CM, Bakker PA. The rhizosphere microbiome and plant health. Trends plant sci. 2012; 17:478-86. https://doi.org/10.1016/j.tplants.2012.04.001.

40. Finkel OM, Castrillo G, Paredes SH, González IS, Dangl JL. Understanding and exploiting plant beneficial microbes. Curr Opin Plant Biol. 2017;38:155-63.doi: 10.1016/j.pbi.2017.04.018. 
41. Pereira LB, Andrade GS, Meneghin SP, Vicentini R, Ottoboni LM. Prospecting plant growth-promoting bacteria isolated from the rhizosphere of sugarcane under drought stress. Curr microbiol. 2019;76:1345-54. doi: 10.1007/s00284-019-01749-x.

42. Dagnaw F, Assefa F, Gebrekidan H, Argaw, A. Characterization of plant growth promoting bacteria from sugarcane (Saccharum officinarum L.) rhizosphere of Wonji-Shoa Sugar Estate and farmers landraces of Ethiopia. Biotechnol. 2015;14, 58.

43. Baldani JI, Reism VM, Baldani VL, Döbereiner J. A brief story of nitrogen fixation in sugarcanereasons for success in Brazil. Functional Plant Biol. 2002;29:417-23. https://doi.org/10.1071/PP01083.

44. Gao X, Wu Z, Liu R, Wu J, Zeng Q, Qi Y. Rhizosphere Bacterial Community Characteristics over Different Years of Sugarcane Ratooning in Consecutive Monoculture. BioMed Res Int. 2019; 4943150. https://doi.org/10.1155/2019/4943150.

45. Hara S, Morikawa T, Wasai S, Kasahara Y, Koshiba T, Yamazaki K, Fujiwara T, Tokunaga T, Minamisawa K. Identification of Nitrogen-Fixing BradyrhizobiumAssociated With Roots of FieldGrown Sorghum by Metagenome and Proteome Analyses. Front. Microbiol. 2019. https://doi.org/10.3389/fmicb.2019.00407.

46. de Matos GF, Zilli JE, de Araújo JLS, Parma MM, Melo IS, Radl V, Baldani JI, Rouws LFM. Bradyrhizobium saccharisp. nov., a legume nodulating bacterium isolated from sugarcane roots. Arch Microbiol. 2019. doi 10.1007/s00203-017-1398-6.

47. Jiménez DJ, Montaña JS, Martínez MM. Characterization of free nitrogen fixing bacteria of the genus azotobacterin organic vegetable-grown colombian soils. Brazilian J Microbiol. 2011;42: ISSN 1517-8382.

48. Dobereiner J. Nitrogen-fixing bacteria of the genus Beijerinckia Derx in the rhizosphere of sugar cane. Plant Soil. 1961; 15: 211-6. https://doi.org/10.1007/BF01400455.

49. Pankievicz VCS, Irving TB, Maia LGS, Ané JM. Are we there yet? The long walk towards the development of efficient symbiotic associations between nitrogen-fixing bacteria and nonleguminous crops. BMC Biol. 2019;17:99.

50. Nassar R, Seleem EA, Caruso G, Sekara A, Abdelhamid MT. The Nitrogen-Fixing Bacteria-Effective Enhancers of Growth and Chemical Composition of Egyptian Henbane under Varied Mineral N Nutrition. Agronomy. 2020;10:921. https://doi.org/10.3390/agronomy10070921.

51. Sun S, Chen Y, Cheng J, Li Q, Zhang Z, Lan Z. Isolation, characterization, genomic sequencing, and GFP-marked insertional mutagenesis of a high-performance nitrogen-fixing bacterium, Kosakonia radicincitans GXGL-4A and visualization of bacterial colonization on cucumber roots. Folia Microbiol. (Praha), 2018;63(6):789-802. doi: 10.1007/s12223-018-0608-1.

52. Bahulikar RA, Chaluvadi SR, Torres-Jerez I, Mosali J, Bennetzen JL, Udvardi M. Nitrogen fertilization reduces nitrogen fixation activity of diverse diazotrophs in Switch grass Roots. Phytobiomes J. PBIOMES-09. 2020. https://doi.org/10.1094/PBIOMES-09-19-0050-FI. 
53. Solanki MK, Wang FY, Wang Z, Li CN, Lan TJ, Singh RK, Singh P, Yang LT, Li YR. Rhizospheric and endospheric diazotrophs mediated soil fertility intensification in sugarcane-legume intercropping systems. J. Soil Sediment. 2018. https://doi.org/10.1007/s11368-018-2156-3.

54. Solanki MK, Wang Z, Wang FY, Li CN, Lal CG, Singh RK, Malviya MK, Singh P. Yang LT, Li YR. Assessment of diazotrophic proteobacteria in sugarcane rhizosphere when intercropped with legumes (Peanut and Soybean) in the field. Front Microbiol. 2020;11:1814, doi: 10.3389/fmicb.2020.01814.

55. Singh RK, Singh P, Li HB, Song QQ, Guo DJ, Solanki MK, Verma KK, Malviya MK, Song XP, Laxmanan $P$, Yang LT, Li YR. Diversity of nitrogen-fixing rhizobacteria associated with sugarcane: a comprehensive study of plant-microbe interactions for growth enhancement in Saccharum spp. BMC plant Biol. 2020;20:220. https://doi.org/10.1186/s12870-020-02400-9.

56. Espenberg M, Truu M, Mander Ü, Kasak K, Nõlvak H, Ligi T, Oopkaup K, Maddison, M, Truu J. Differences in microbial community structure and nitrogen cyclingin natural and drained tropical peatland soils. Sci. Rep. 2018;8:4742. https://doi.org/10.1038/s41598-018-23032-y.

57. Ueki A, Akasaka H, Satoh A, Suzuki D, Ueki K. Prevotellapaludivivens sp. nov., a novel strictly anaerobic, Gram-negative, hemicellulose-decomposing bacterium isolated from plant residue and rice roots in irrigated rice-field soil. Int J Syst Evol Microbiol. 2007;57(8):1803-1809. doi: 10.1099/ijs.0.64914-0.

58. Masuda Y, Yamanaka H, Xu ZX, Shiratori Y, Aono T, Amachi S, Senoo K, Itoh H. Diazotrophic Anaeromyxobacterisolates from soils. Appl Environ Microbiol. 2020. doi:10.1128/AEM.00956-20.

59. Reis $V$, Lee $S$, Kennedy $C$. Biological nitrogen fixation in sugarcane. In associative and endophytic nitrogen-fixing bacteria and cyanobacterial associations. 2007; 213-232.

60. Sessitsch A, Hardoim P, Döring J, Weilharter A, Krause A, Woyke T. Functional characteristics of an endophyte community colonizing rice roots as revealed by metagenomic analysis. Mol Plant Microbe Interact. 2012;25:28-36. doi: 10.1094/MPMI-08-11-0204.

61. Bao Z, Okubo T, Kubota K, Kasahara Y, Tsurumaru H, Anda M, et al. Metaproteomic identification of diazotrophic methanotrophs and their localization in root tissues of field-grown rice plants. Appl Environ Microbiol. 2014;80:5043-52. doi:10.1128/AEM.00969-14.

62. Yoneyam T, Terakado-Tonooka J, Minamisawa K. Exploration of bacterial N2-fixation systems in association with soil-grown sugarcane, sweet potato, and paddy rice: a review and synthesis. Soil Sci. Plant Nutr. 2017;63:578-90, https://doi.org/10.1080/00380768.2017.1407625.

63. Rosenblueth M, Ormeño-Orrillo E, López-López A, Rogel MA, Reyes-Hernández BJ, Martínez-Romero JC, et al. Nitrogen fixation in cereals. Front. Microbiol. 2018;9:1794. doi:10.3389/fmicb.2018.01794.

64. Sy A, Giraud E, Jourand P, Garcia N, Willems A, DeLajudie P, et al. Methylotrophic Methylobacterium bacteria nodulate and fix nitrogen in symbiosis with legumes. J bacteriol. 2011;183:214-20. doi: 10.1128/JB.183.1.214-220.2001.

\section{Figures}



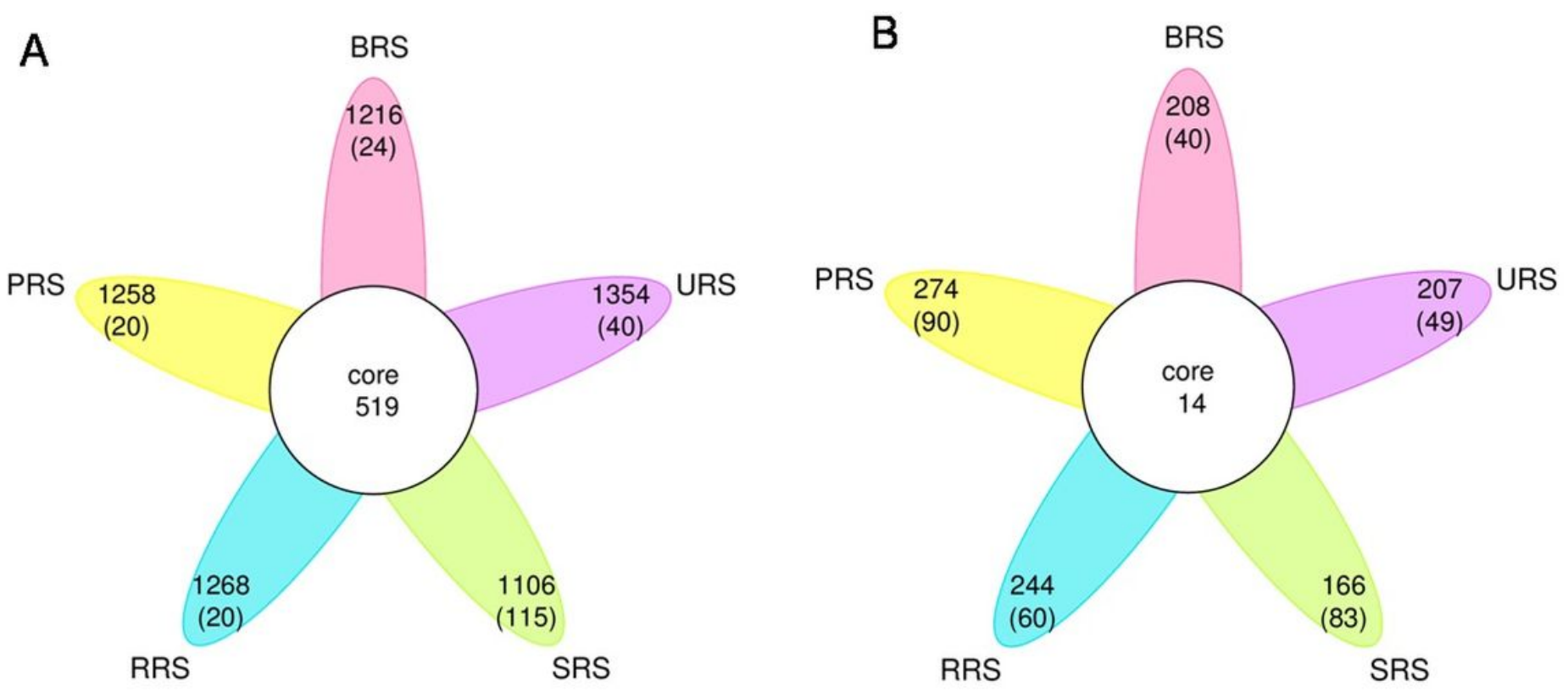

\section{Figure 1}

Venn diagram showing the OTUs of all sugarcane species (A) 16S and (B) nifH gene. S. officinarum L. cv Badila (BRS), S. barberi Jesw. cv pansahi (PRS), S. robustum (RRS), S. spontaneum (SRS), and S. sinense Roxb. cv. Uba (URS)
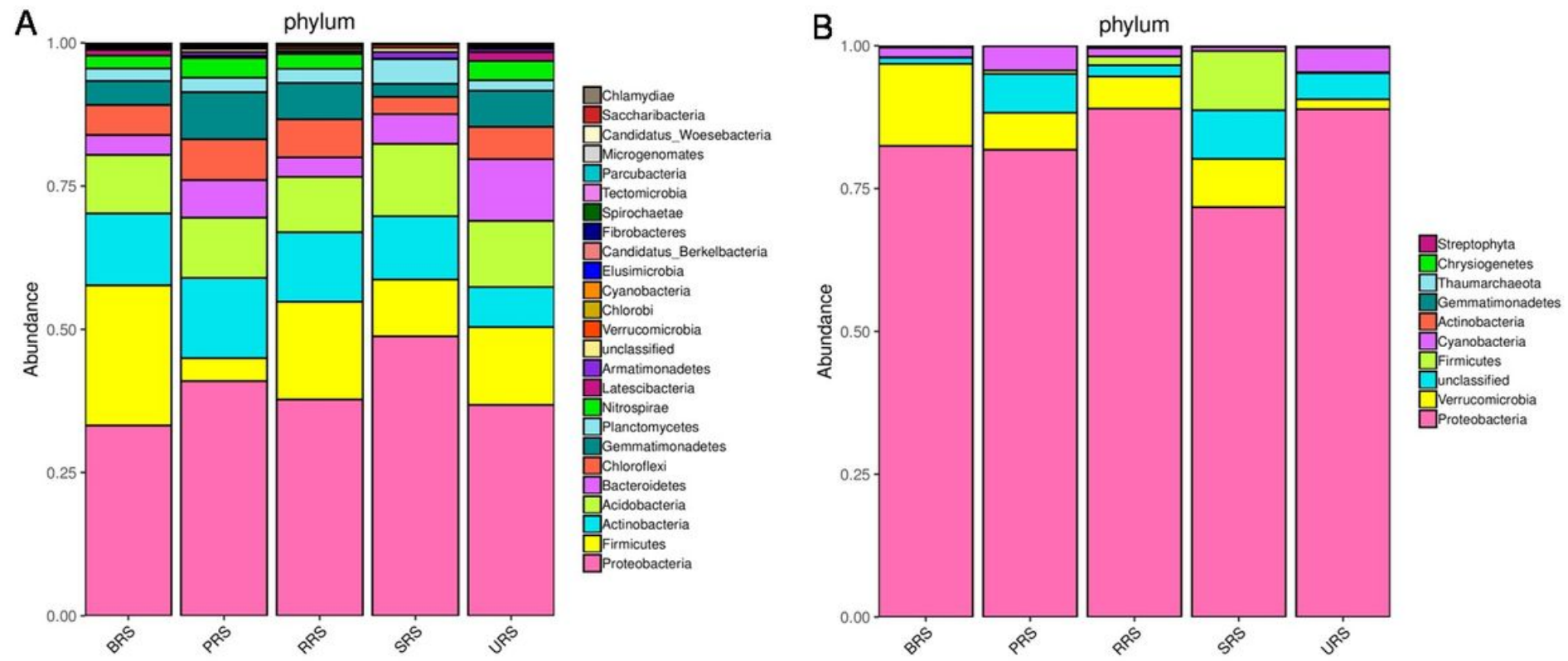

\section{Figure 2}

Community composition analysis at phyllum level of all sugarcane species (A) 16S rRNA and (B) nifH gene. S. officinarum L. cv Badila (BRS), S. barberi Jesw. cv pansahi (PRS), S. robustum (RRS), S. spontaneum (SRS), and S. sinense Roxb. cv. Uba (URS) 
A

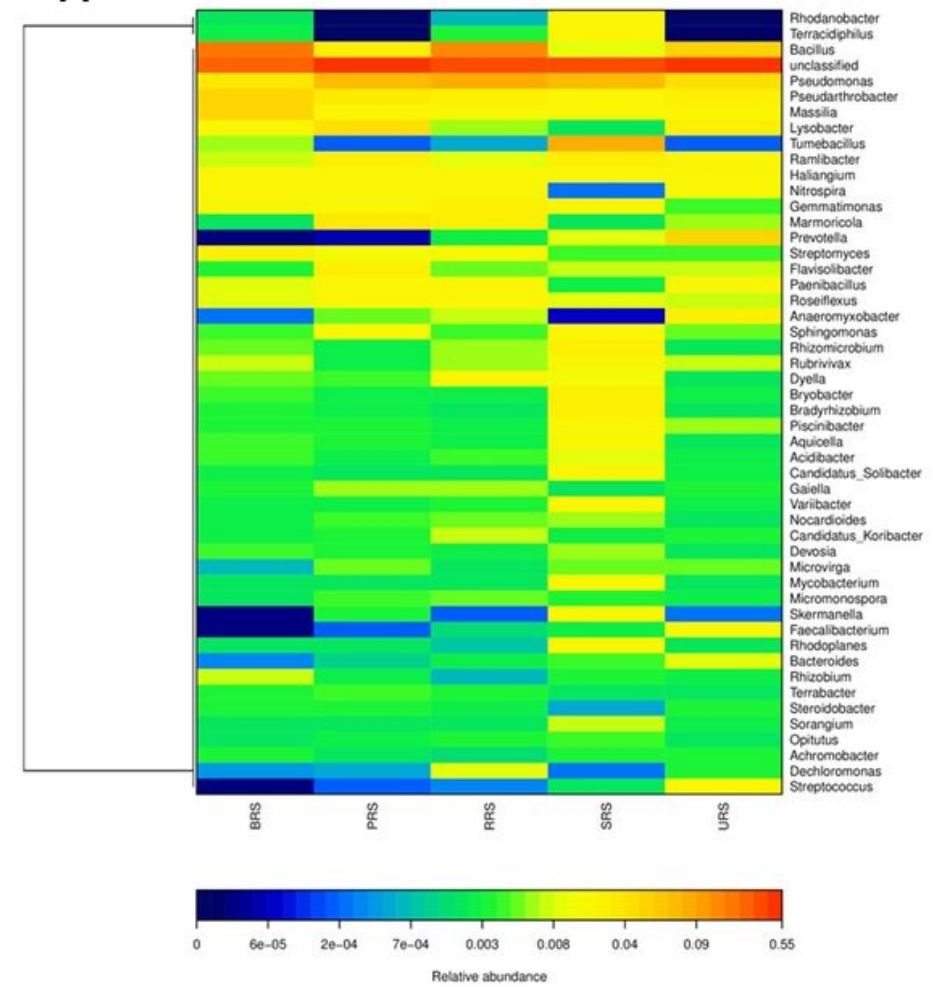

B

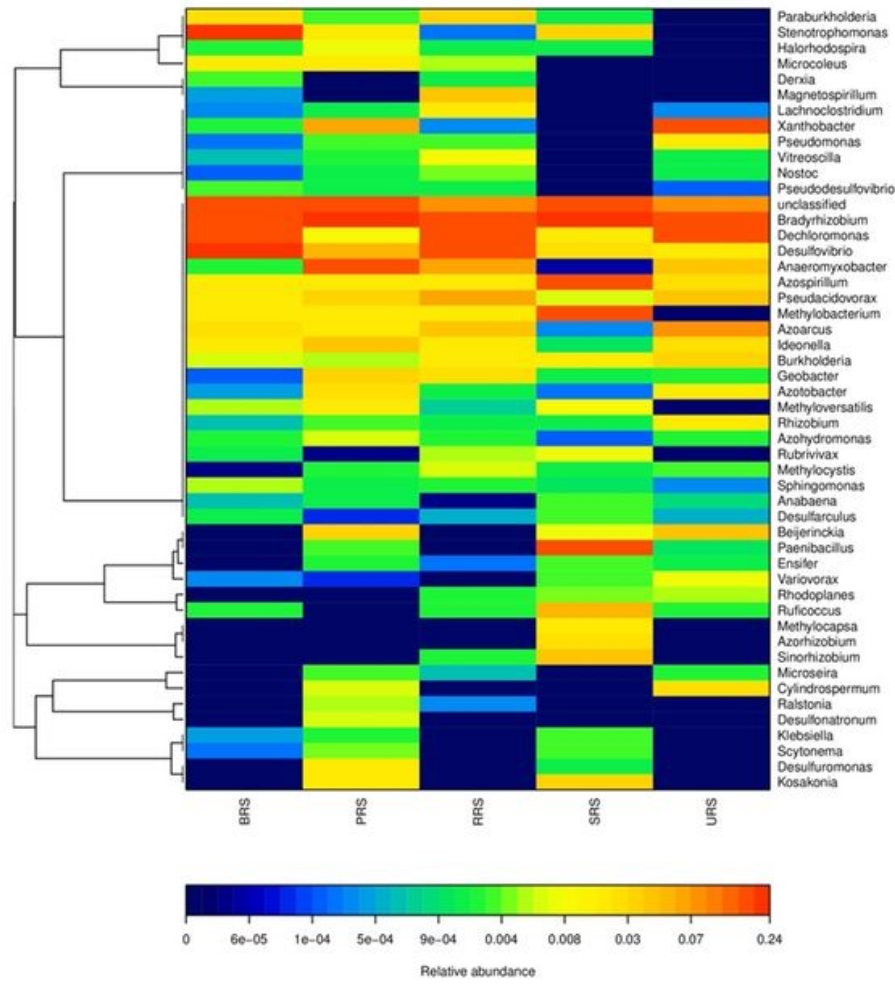

Figure 3

Heat map showing the abundances of bacterial communities at genus level of all sugarcane species (A) 16S rRNA and (B) nifH gene. S. officinarum L. cv Badila (BRS), S. barberi Jesw. cv pansahi (PRS), S. robustum (RRS), S. spontaneum (SRS), and S. sinense Roxb. cv. Uba (URS)
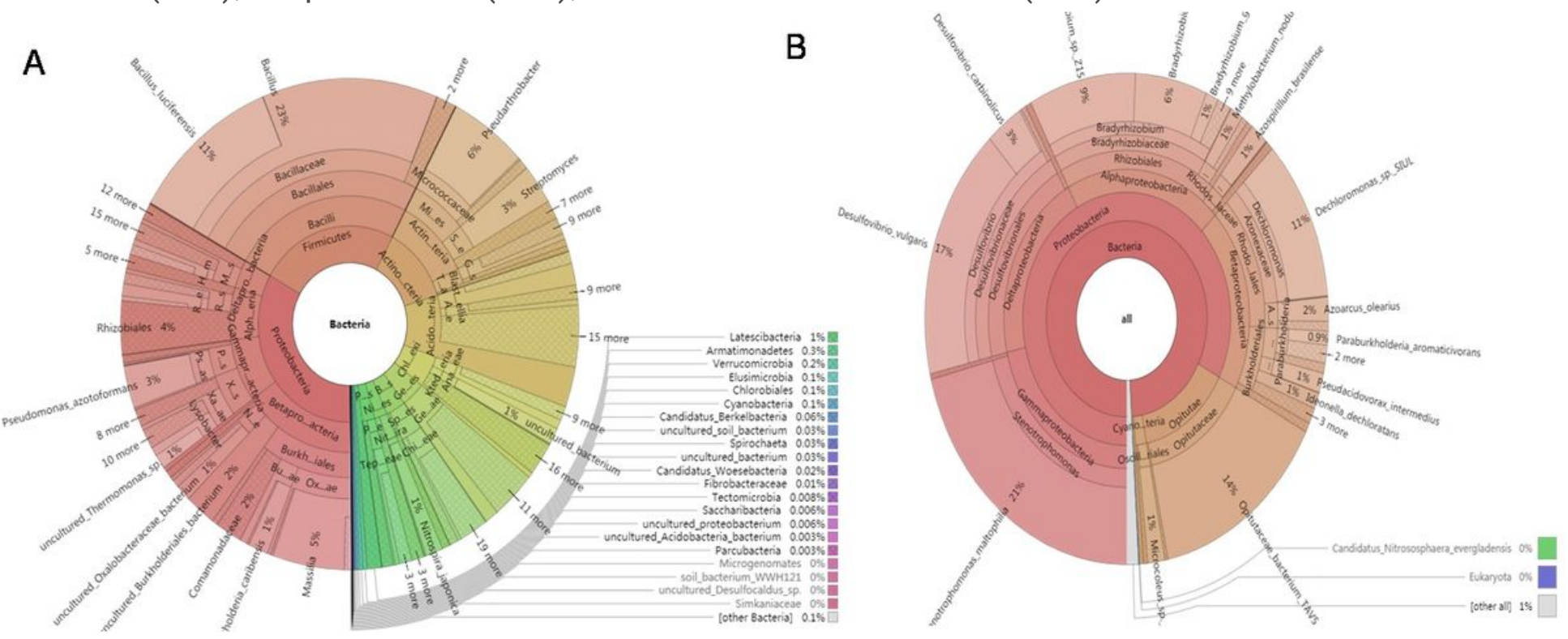

Figure 4

Korona analysis (A) 16S rRNA (B) nifH. Different colored regions represent different species, the circles from inside to out represent the classification levels from the phylum to genus. S. officinarum L. cv Badila 
(BRS), S. barberi Jesw. cv pansahi (PRS), S. robustum (RRS), S. spontaneum (SRS), and S. sinense Roxb. cv. Uba (URS)

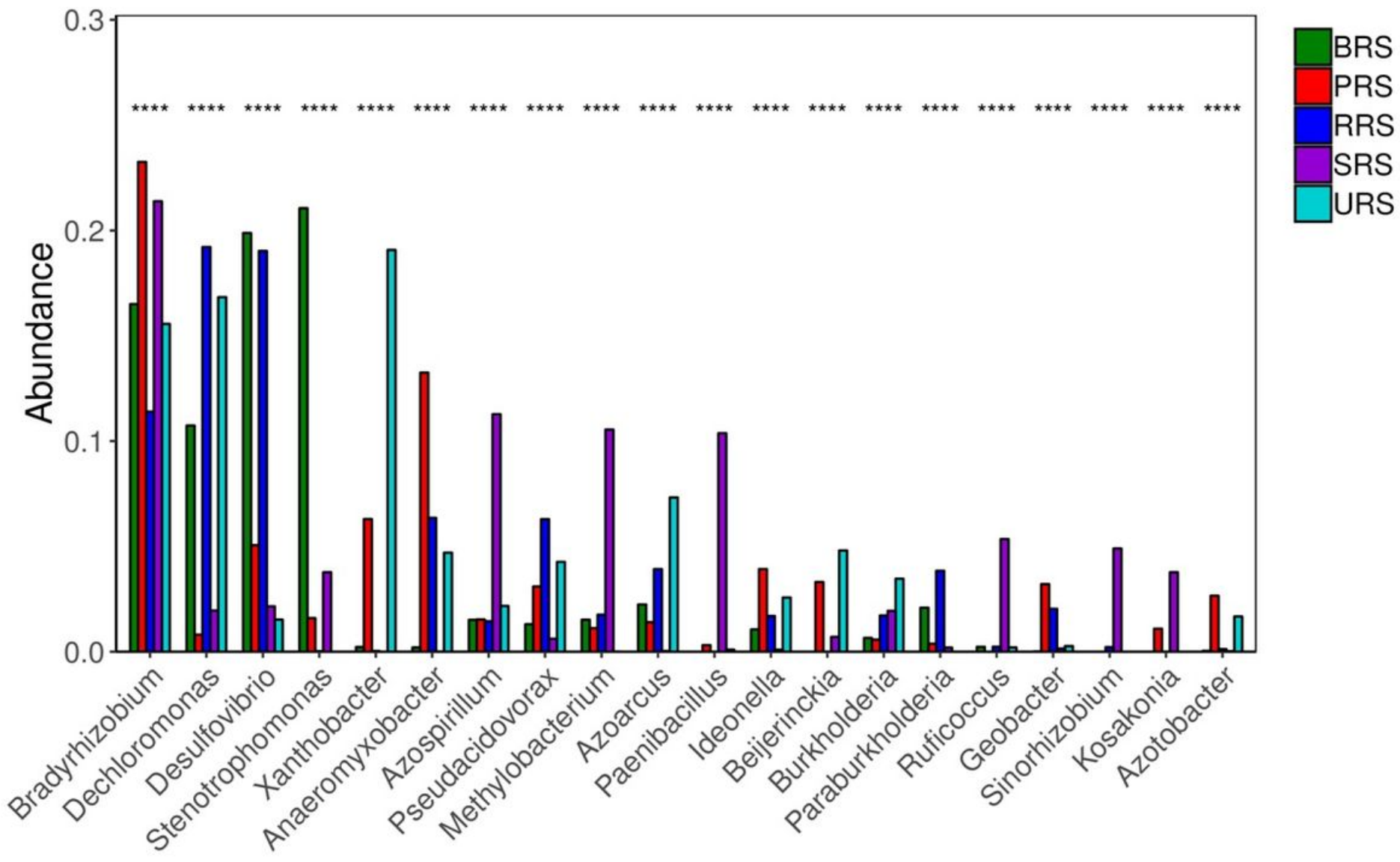

Figure 5

The relative abundances of the top 20 diazotrophs at the genus level of all samples. S. officinarum L. cv Badila (BRS), S. barberi Jesw. cv pansahi (PRS), S. robustum (RRS), S. spontaneum (SRS), and S. sinense Roxb. cv. Uba (URS) 

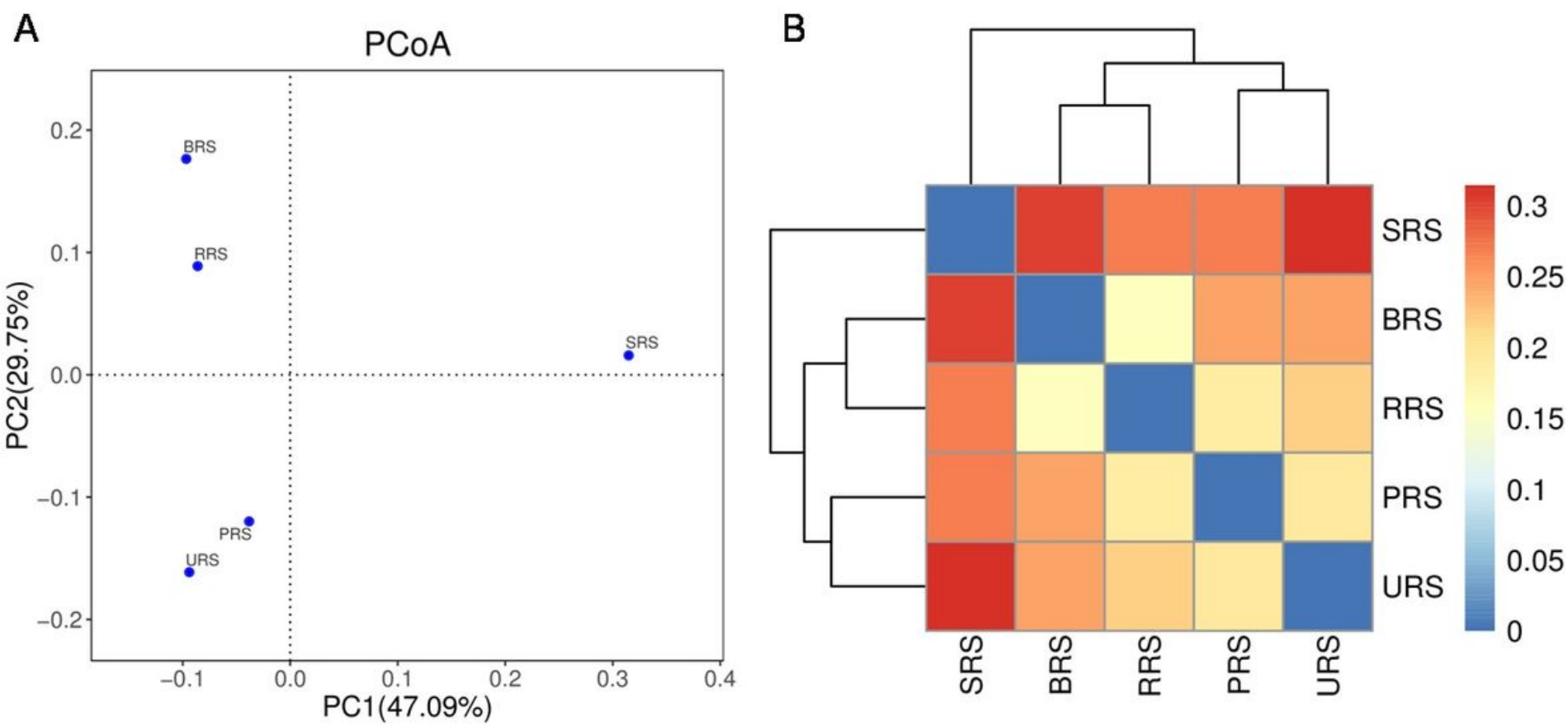

Figure 6

Beta diversity analysis to estimate the dissimilarity and similarity of $16 \mathrm{~S}$ bacterial communities and composition among different samples. (a) Principal coordinated analysis (PCOA) derived from dissimilarity matrix of weighted UniFrac distance. (b) Multi-sample differential matrix heat map weighted UniFrac based cluster analysis of bacterial community composition among different samples. $\mathrm{S}$. officinarum L. cv Badila (BRS), S. barberi Jesw. cv pansahi (PRS), S. robustum (RRS), S. spontaneum (SRS), and S. sinense Roxb. cv. Uba (URS)
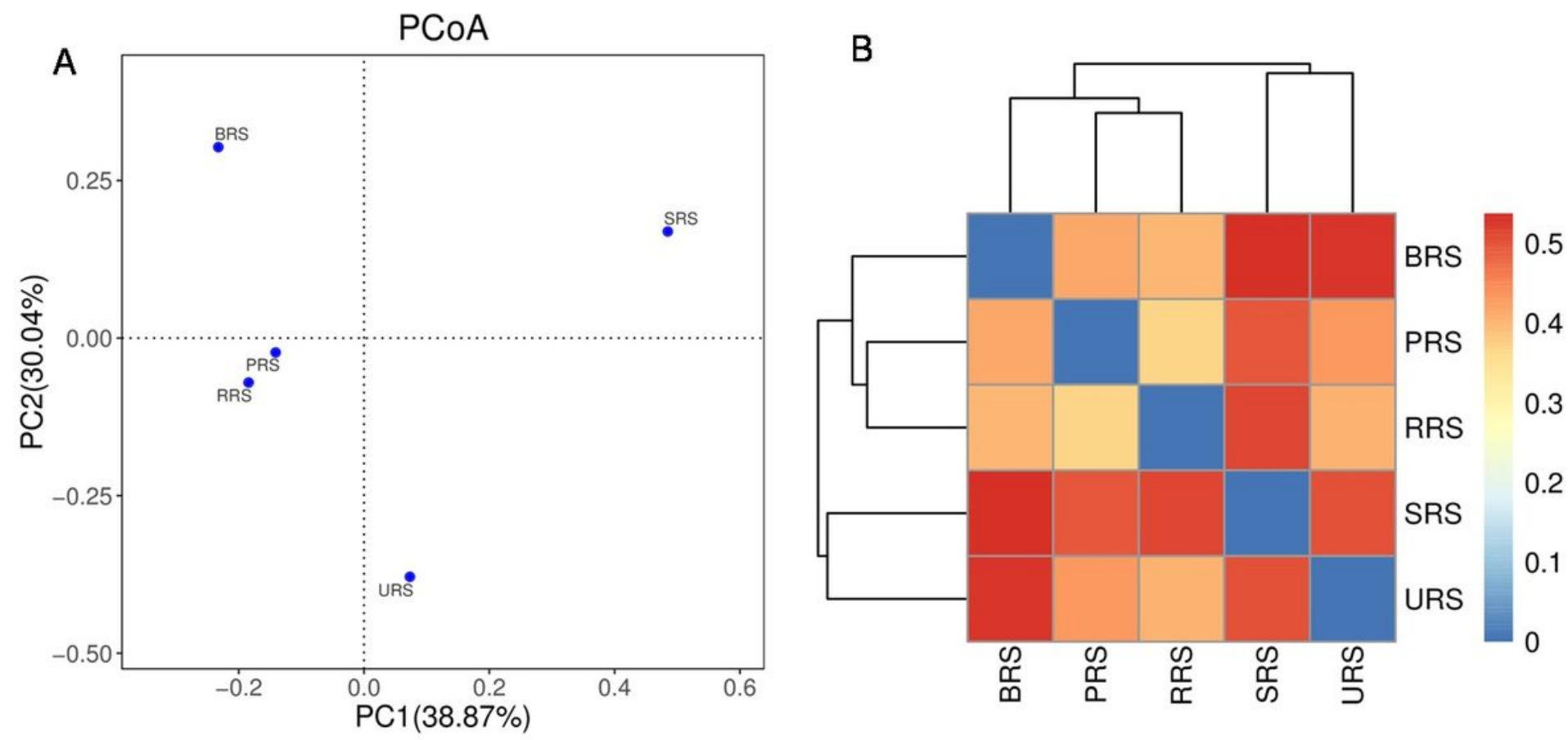
Figure 7

Beta diversity analysis to estimate the dissimilarity and similarity of nifH bacterial communities and composition among different samples. (a) Principal coordinated analysis (PCoA) derived from dissimilarity matrix of weighted UniFrac distance. (b) Multi-sample differential matrix heat map weighted UniFrac based cluster analysis of bacterial community composition among different samples. S. officinarum L. cv Badila (BRS), S. barberi Jesw. cv pansahi (PRS), S. robustum (RRS), S. spontaneum (SRS), and S. sinense Roxb. cv. Uba (URS)

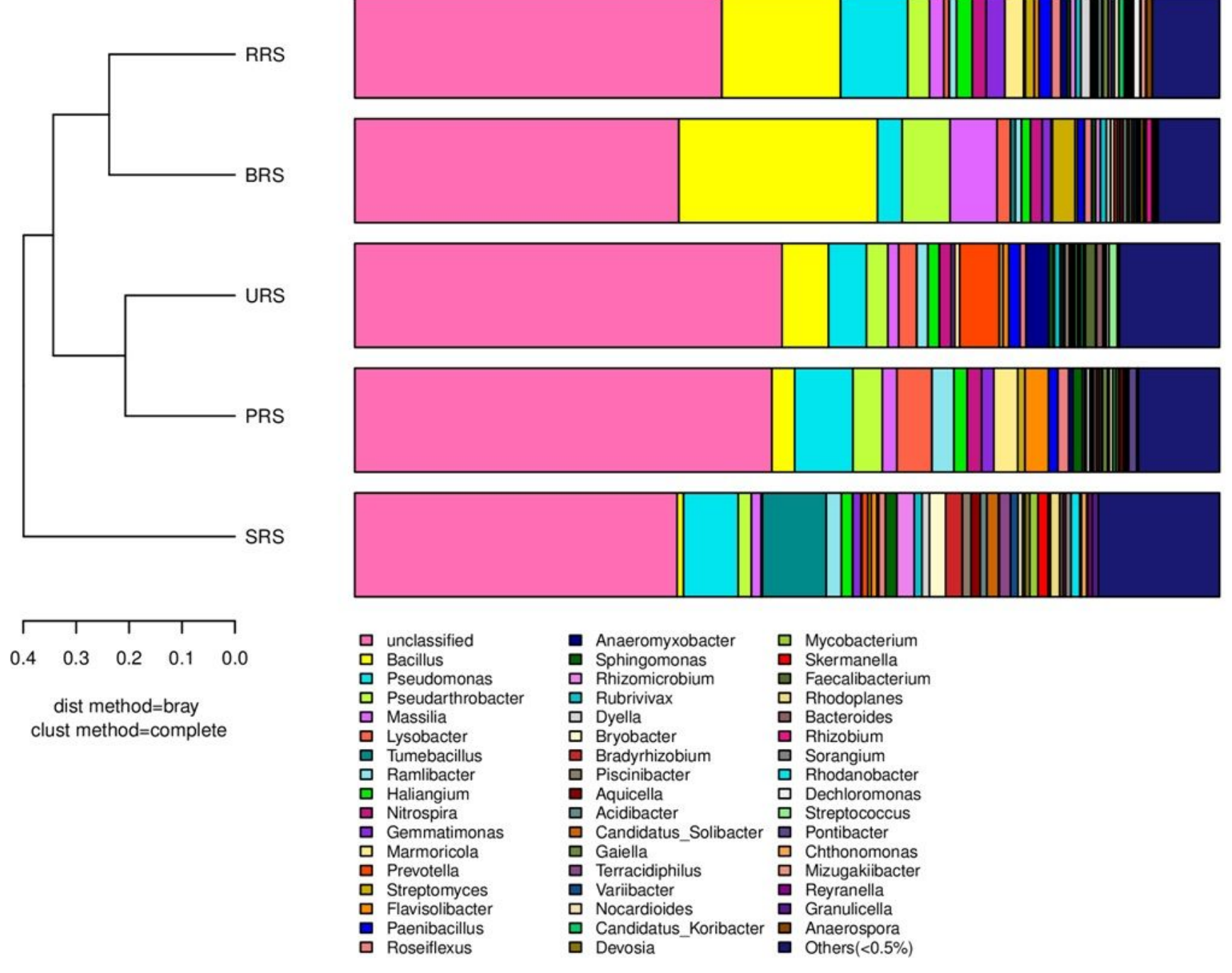

\section{Figure 8}

A combination of horizontal multi-sample similarity trees and histograms of $16 \mathrm{~S}$ genus. On the left is hierarchical clustering between samples based on community composition (bray-curtis algorithm), and on the right is a column chart of the sample's community structure. S. officinarum L. cv Badila (BRS), S. barberi Jesw. cv pansahi (PRS), S. robustum (RRS), S. spontaneum (SRS), and S. sinense Roxb. cv. Uba (URS). 

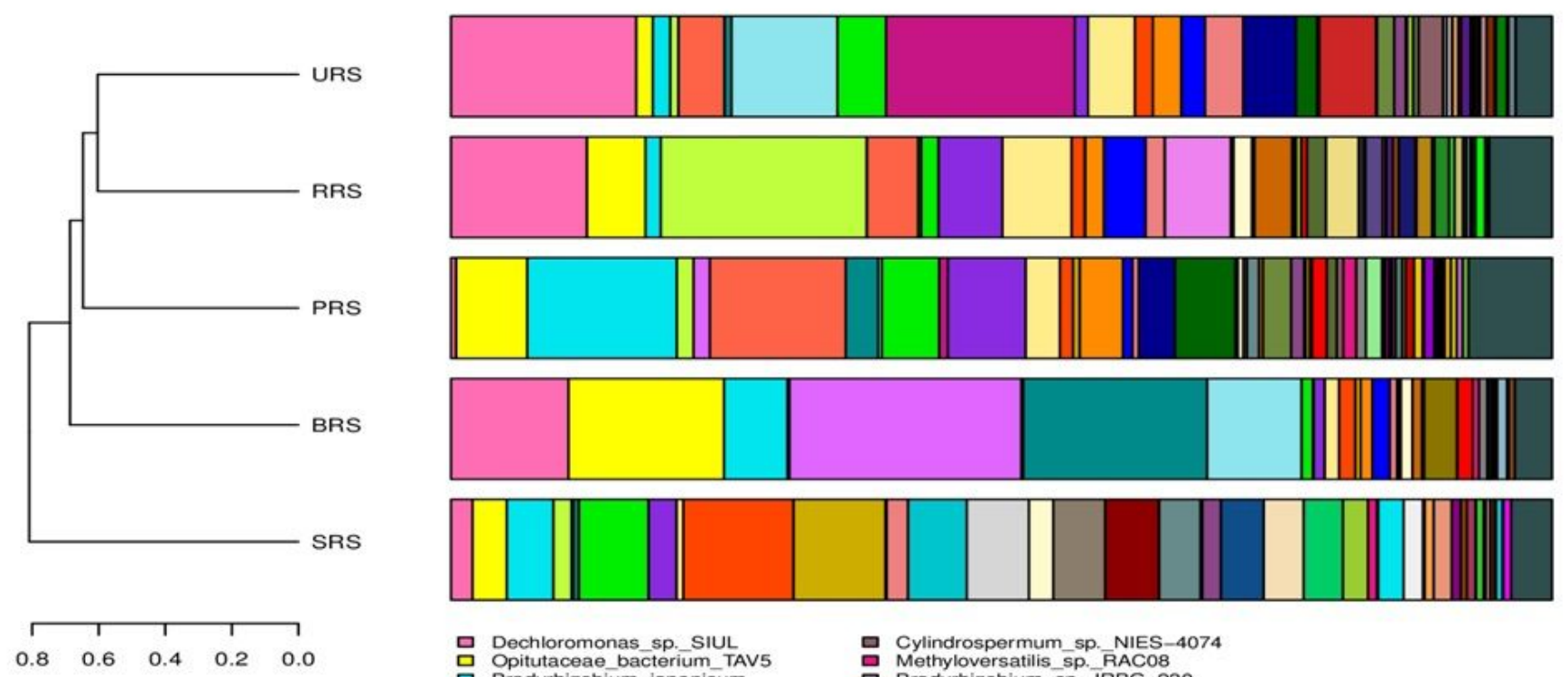

dist method=bray clust method $=$ complete

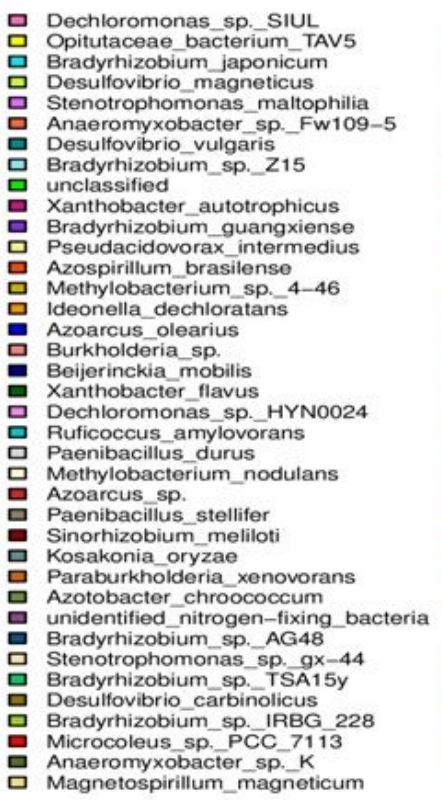

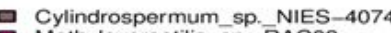

Methyloversatilis_sp. RACO8

Bradyrhizobium_sp._IRBG_230

Azorhizobium_caulinodan

Bradyrhizobium_sp.

Geobacter_bemidjiensis

Azospirillum sp. CFH 70021

Methylocapsa palsarum

Bradyrhizobium Sp. CCBAU 101065

Bradyrhizobium_sp._ISA2507

Bradyrhizobium_sp._ORS 285

Geobacter sp. M18

SEMIA 6014

oscoviense

-

Bradyrhizobium oligotrophicum

Bradyizobiam_oligotrop

Vitreosintatinosus

Halorhodospira_halophila

Rhodoplanes_elegans

位orans

Variovorax sp. HW608

Geobacter pickeringi

Rhizobium jaguaris

Desulfuromonas sp. DDH964

Bradyrhizobium sp. M12

Dechloromonas aromatica

Sphingomonas paucimobilis

Pseudomonas sp. IPPW-3

Desulfuromonas soudanensis

Beijerinckia_derxii

Desulfonatronum thiosulfatophilum

Ralstonia_sp._S1SM82

Geobacter_metallireducens

Azomonas agilis
Others $(<0.5 \%)$

\section{Figure 9}

A combination of horizontal multi-sample similarity trees and histograms of nifH genus. On the left is hierarchical clustering between samples based on community composition (bray-curtis algorithm), and on the right is a column chart of the sample's community structure. S. officinarum L. cv Badila (BRS), S. barberi Jesw. cv pansahi (PRS), S. robustum (RRS), S. spontaneum (SRS), and S. sinense Roxb. cv. Uba (URS).

\section{Supplementary Files}

This is a list of supplementary files associated with this preprint. Click to download. 
- AdditionalFile1.pdf

- AdditionalFile2.pdf 